\title{
Correlation between plasmatic vitamin D level and refractive status in children with disabilities
}

\author{
Larisa Bianca Holhos', Teodora-Laura Holhos'2, Mihaela Cristiana Coroi', \\ Carina Petricau ${ }^{3}$, Liviu Lazar ${ }^{1}$ \\ ${ }^{1}$ Faculty of Medicine and Pharmacy, University of Oradea, Romania \\ ${ }^{2}$ Faculty of Medicine and Pharmacy, Arad University, Romania \\ ${ }^{3}$ Allergy Outpatient Unit, "Prof. Dr. Octavian Fodor" Regional Institute of Gastroenterology and \\ Hepatology, Cluj-Napoca, Romania
}

\begin{abstract}
Introduction. Literature confirms that refractive errors are the most common, easily corrected, eye morbidity in children with disabilities. Early intervention such as wearing eyeglasses can positively impact the lives of these children. The implication of vitamin D status is investigated as a possible proactive measure in eye conditions. Aim. The current study proposed to asses the refractive status as well as vitamin D plasmatic level in 161 children. Another aim was to investigate whether myopia corelates with a lower plasmatic vitamin D level.

Methods. A retrospective case-control study was done on 161 children, divided into two groups: the study group (children with disabilities) and the contol group (children without disabilities). The age range of children included in the study was from 5 to 16 years old.

Results. Refractive errors were found to be more frequent in the group of children with disabilities and of these, astigmatism was the most frequent refractive disorder identified. Also, the plasmatic vitamin $D$ level was found to be lower in those with myopia reguardless of disability status.

Conclusions. Children with disabilities are diagnosed with refractive errors twice more frequenty than their healthy peers. Parents, medical staff and teachers should be aware of this risk factor and be more attentive because the presence of uncorrected refractive disorders may not be visible in most children, especially those with special needs.
\end{abstract}

Keywords: refractive errors, children, vitamin D level

\section{INTRODUCTION}

Vision development takes place in early childhood, when all the sensitive and motor functions are combined in order to acquire the proper language skills and other items that define healthy human beings.

Vision screening in children is insufficiently utilized, thus various ocular pathologies are often detected too late, narrowing treatment options. Visual function is indispensable in our daily activities, so that uncorrected refractive errors are a major public health problem worldwide, commonly among children [1]. Different studies conducted on children with disabilities show that this category presents a higer prevalence of refractive errors than their clinically healthy peers. Uncorrected refractive errors in children can affect their cognitive development as well as socio-professional status.

According to the present estimations, worldwide, there are aproximately 1.4 million children with uncorrected refractive errors. Studies concluded that children without refractive errors have better cognitive development and social life compared to their peers diagnosed with refractive errors. Different restrictions are present in the life of children with refractive errors, even if they benefit from aerial or contact lense correction. Unrecognized refractive er-

Corresponding authors: 
rors in children with disabilities can add to their preexisting condition, limiting their lives in all areas.

Refractive disorders represent the most common cause of visual dysfunction in children with disabilities. Ophthalmic examination is often ommited in these children because the emphasis is placed of management of other health issues such as cardiac and gastro-intestinal conditions [2].

The cummulative effect of a disability and an uncorrected refractive error will negatively impact the lives of these children. Healthcare workers and families need to be aware of the ocular disorders of these children with special needs. A vision screening evaluation is recommended before the age of 6 , when they enter school. The human eye is strictly dependent on vitamin D level [3], such that emmetropization was found to occur physiologically at an adequate level of plasmatic vitamin $\mathrm{D}$.

Vitamin D is a multifunctional hormone imperative for eye health. Environmental factors like dim room illumination where a child studies and plays, various levels of sun exposure and plasmatic vitamin D level can impact refractive status. Different studies have been done regarding the link between room illumination, sun exposure and plasmatic vitamin D levels and occurrence of myopia in children.

\section{AIM}

The aim of this study was to assess the refractive status of children with special needs, their plasmatic vitamin D level and to compare with those of children from the control group, without disabilities. Another aim of this study was to analyze if children with myopia have a lower level of plasmatic vitamin D.

\section{MATERIAL AND METHOD}

A retrospective case-control study was done on 161 children at a private medical practice located in Marghita, Bihor county. The study was conducted between January 2019 to August 2020. The study group comprised of 80 children diagnosed with a disability. The control group consisted of 81 children without disabilities. This study took into account children with the age from 5 to 16 years old. Inclusion criteria: age between 5 to 16 years old; children without disabilities (control group); children diagnosed with disabilities (study group). Exclusion criteria: children less than 5 years or more than 16 years old. All the children were ohthalmologically tested to detect if they presented a refractive disorder that needed correction. Canon Full Auto-Ref Keratometer RK-F2 was used to assess the diopter power of the eyes before and after cycloplegia. Data about refractive status recorded in this study are after cycloplegia and proper eye correction.

Plasmatic vitamin D level of all the children was assessed at local laboratories using the same standardized methods of analysis, units $(\mathrm{ng} / \mathrm{ml})$ and reference range values for $25(\mathrm{OH})$ Vitamin D. Quantitative measurement of plasmatic vitamin $\mathrm{D}$ was performed using the immunochemical method with the help of the electrochemoiluminiscence. This method measures the total level of vitamin D, which encompases vitamin D3, vitamin D2 and other hydroxylated metabolites of vitamin D.

It is widely accepted that the normal value of plasmatic $25(\mathrm{OH})$ vitamin $\mathrm{D}$ is $>30 \mathrm{ng} / \mathrm{ml}$ or $>75 \mathrm{mmol} / 1$. According to the American Society of Endocrinology recomendations ${ }^{1}$ its ideal value is $40-60 \mathrm{ng} / \mathrm{ml}$. The following vitamin $\mathrm{D}$ value classification was considered for this study: suboptimal level - 20-30 ng/ml; mild deficiency - 10-20 ng/ml; severe deficiency $5-10 \mathrm{ng} / \mathrm{ml}$; very severe deficiency $<5 \mathrm{ng} / \mathrm{ml}$.

All the parents of the children included in the study were informed reguarding with the protocol of the study and gave their written informed consent. The present study was conducted in accordance with the World Medical Association Code of Ethics from 1967, Declaration of Helsinki. The ethical consent was given by Faculty of Medicine and Pharmacy of Oradea, University of Oradea, no 14/23.12.2020.

A database was created and analysis was done with the help of the medical statistics program MedCalc, version 12.5.0.0.

Categorical data was expressed in absolute numbers. Continuous data was expressed as a mean \pm standard deviation (SD) (with 95\% Confidence Interval). Variables were analysed using the chi-square test and Student's t-test for independent groups. The ANOVA test was used for more than three groups. The $\mathrm{p}$ values $<0.05$ were considered statistically significant.

\section{RESULTS}

The number of emmetropes was significantly higher in the group of children without disabilities: 61 out of $81(76.5 \%)$ vs. 36 out of $80(45 \%)$, $\mathrm{p}<0.0001$ (Figure 1).

The distribution of different types of refractive errors was somewhat similar for children with and without disabilities $(\mathrm{p}=0.3391)($ Table 1$)$. 


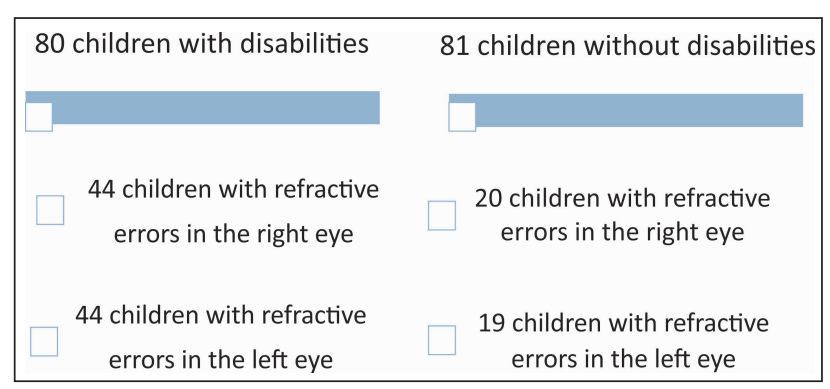

FIGURE 1. Distribution of refractive errors in each of the two study groups

TABLE 1. Distribution of refractive errors according to groups

\begin{tabular}{|l|c|c|c|}
\hline $\begin{array}{c}\text { Refractive } \\
\text { errors }\end{array}$ & $\begin{array}{c}\text { Group of } \\
\text { children } \\
\text { with disabilities } \\
(\mathbf{n = 8 0 )}\end{array}$ & $\begin{array}{c}\text { Group of } \\
\text { children without } \\
\text { disabilities } \\
(\mathbf{n}=\mathbf{8 1})\end{array}$ & $\begin{array}{c}\text { Statistical } \\
\text { significance } \\
\mathbf{( p )}\end{array}$ \\
\cline { 1 - 3 } Myopia & $12(15.0 \%)$ & $8(9.9 \%)$ & \multirow{2}{*}{$0.3391^{*}$} \\
\cline { 1 - 3 } Hyperopia & $7(8.75 \%)$ & $4(4.9 \%)$ & \\
\hline Astigmatism & $25(31.25 \%)$ & $7(8.7 \%)$ & \\
\hline
\end{tabular}

$n=$ number of patients per group, $p=$ null hypothesis value

* - chi-square test

The level of plasmatic Vitamin D in children with disabilities and refractive errors was $29.2 \mathrm{ng} / \mathrm{ml}$ $(\mathrm{SD}=4.8)$, and for those without any refractive errors it was $36.5 \mathrm{ng} / \mathrm{ml}(\mathrm{SD}=7.9)$, which shows a statistically significant difference $(\mathrm{p}<0.0001)$ (Table 2).

TABLE 2. Level of plasmatic vitamin $D$ in children with disabilities

\begin{tabular}{|c|c|c|c|}
\hline $\begin{array}{c}\text { Vitamin D } \\
\text { level }\end{array}$ & $\begin{array}{c}\text { Children with } \\
\text { disabilities } \\
\text { and refractive } \\
\text { errors }\end{array}$ & $\begin{array}{c}\text { Children with } \\
\text { disabilities } \\
\text { without } \\
\text { refractive errors }\end{array}$ & $\begin{array}{c}\text { Statistical } \\
\text { significance } \\
\text { (p) }\end{array}$ \\
\hline $\begin{array}{c}\mathrm{ng} / \mathrm{ml} \text {-average } \\
\text { (DS) }\end{array}$ & $29.2(4.8)$ & $36.5(7.9)$ & $<0.0001^{*}$ \\
\hline
\end{tabular}

*Student's $t$-test for independent groups; $p=$ null hypothesis value

The Student's t-test for independent groups performed on children without disabilities reveals an average value of Vitamin D of $44.6 \mathrm{ng} / \mathrm{ml}(\mathrm{SD}=6.3)$ for children without refractive errors compared to 34.7 $\mathrm{ng} / \mathrm{ml}(\mathrm{SD}=8.8)$ for children diagnosed with refractive errors. The difference in this case is also very significant $(\mathrm{p}<0.0001$, Student's t- test for independent groups) (Table 3$)$.

TABLE 3. Vitamin D level of children without disabilities

\begin{tabular}{|c|c|c|c|}
\hline $\begin{array}{c}\text { Vitamin D } \\
\text { level }\end{array}$ & $\begin{array}{c}\text { Children } \\
\text { without } \\
\text { disabilities } \\
\text { and refractive } \\
\text { errors }\end{array}$ & $\begin{array}{c}\text { Children } \\
\text { without } \\
\text { disabilities, } \\
\text { with refractive } \\
\text { errors }\end{array}$ & $\begin{array}{c}\text { Statistical } \\
\text { significance } \\
(\mathbf{p})\end{array}$ \\
\hline $\begin{array}{c}\mathrm{Ng} / \mathrm{ml}- \\
\text { average (DS) }\end{array}$ & $44.6(6.3)$ & $34.7(8.8)$ & $<0.0001^{*}$ \\
\hline
\end{tabular}

*Student's t- test for independent groups; $p=$ null hypothesis value
The comparison of vitamin D levels among different types of refractive errors in both groups is shown in Table 4.

TABLE 4. Comparison of vitamin D level according to refractive errors in study groups

\begin{tabular}{|l|c|c|c|}
\hline $\begin{array}{c}\text { Vitamin D level } \\
\text { ng/ml - average } \\
\text { (DS) }\end{array}$ & $\begin{array}{c}\text { Group of } \\
\text { children with } \\
\text { disabilities } \\
\text { (n= 80) }\end{array}$ & $\begin{array}{c}\text { Group of } \\
\text { children } \\
\text { without } \\
\text { disabilities } \\
\text { (n= 81) }\end{array}$ & $\begin{array}{c}\text { Statistical } \\
\text { significance } \\
\text { between } \\
\text { groups (p) }\end{array}$ \\
\hline Myopic & $27.6(3.4)$ & $29.9(1.8)$ & $0.0978^{*}$ \\
\hline Hyperopic & $32.6(6.3)$ & $42.9(11.9)$ & $0.0878^{*}$ \\
\hline Astigmatized & $29.1(4.5)$ & $35.5(8.9)$ & $\mathbf{0 . 0 1 2 9 *}$ \\
\hline
\end{tabular}

$S D=$ standard deviation, $n=$ number of patients per group,

$p=$ null hypothesis value

* - Student test for independent groups

Statistically significant $p$ values are highlighted in bold

Regarding the plasmatic level of vitamin D, no significant differences were found between children with myopia and hyperopia in the two study groups, but if we look at the same values in children with astigmatism, we observe a significantly lower level in those with disabilities. The lowest level of vitamin D was in children with disabilities and myopia, although not significant $(\mathrm{p}=0.0978)$ (Table 4).

The average value of plasmatic vitamin $\mathrm{D}$ in children without refractive errors was $41.6 \mathrm{ng} / \mathrm{ml}$ (standard deviation $=7.8$ ) and in those with refractive error was only $30.7 \mathrm{ng} / \mathrm{ml}(\mathrm{SD}=6.7)$, which represents a statistically significant difference $(\mathrm{p}<0.0001-$ Student test for independent groups) (Table 5).

TABLE 5. Vitamin D level in children with and without refractive disorders

\begin{tabular}{|c|c|c|}
\hline \multicolumn{2}{|c|}{ Vitamin D level ng/ml () } & $\begin{array}{c}\text { Statistical } \\
\text { significance }\end{array}$ \\
\hline $\begin{array}{c}\text { Children without } \\
\text { refractive errors }\end{array}$ & $\begin{array}{c}\text { Children with refractive } \\
\text { errors }\end{array}$ & (p) \\
\hline $41.6(7.8)$ & $30.7(6.7)$ & $<0.0001$ \\
\hline
\end{tabular}

Student test for independent groups

The comparison of the average values for different types of refractive errors is represented in Table 6.

TABLE 6. Vitamin D level for different types of refractive errors for all studied children

\begin{tabular}{|c|c|c|}
\hline $\begin{array}{l}\text { Vitamin D level } \mathrm{ng} / \mathrm{ml} \text { - } \\
\text { average (SD) }\end{array}$ & $\begin{array}{l}\text { Entire group of } \\
\text { children }(n=161)\end{array}$ & $\begin{array}{l}\text { Statistical } \\
\text { significance } \\
\text { (p) }\end{array}$ \\
\hline Myopics $(n=20)$ & $28.5(3.0)$ & \multirow{3}{*}{$<0.005^{*}$} \\
\hline Hyperopic $(n=11)$ & $36.4(9.7)$ & \\
\hline Astigmatics $(n=32)$ & $28.5(6.2)$ & \\
\hline
\end{tabular}


There is a significant increase in the level of plasma vitamin $\mathrm{D}$ in those with hyperopia when we refer to the whole group of patients $(p<0.005)$. The lowest level of vitamin D was found to be in children with myopia $(\mathrm{p}<0.005)$ (Table 6).

\section{DISCUSSIONS}

The literature confirms that refractive errors are the most common eye morbidity in children with disabilities and may benefit from eyeglasses correction. Thus, an early intervention in the form of eyeglasses can have a huge impact on the lives of these children. Parents, medical staff and teachers should pay close attention to this, because the presence of an uncorrected refractive disorder may not be visible in most children, especially those with special needs. There are numerous studies related to this topic [4-7].

Astigmatism is the most common refractive disorder found in children with special needs in this study, and hyperopia is the least common. These results align with the observations from other studies that included children with special needs.

Vora et al. included 70 children with special needs in a study conducted in 2010, in Oman [4]. They had an average age of $4.7 \pm 0.8$ years old. Their refractive status and visual function were assessed, comparing them with a group of 175 clinically healthy children. In the group of children with disabilities, $18.6 \%$, $24.3 \%$ and $27.1 \%$ were identified with hyperopia, myopia and astigmatism, respectively [4].

The study conducted by Kaur et al. in Northern India included 404 children with disabilities and obtained a refractive error rate of $23.6 \%$. Myopia was the most common refractive error, and hyperopia the least common [5]. Astigmatism as more common in children with disabilities was also confirmed by the study conducted in Iran by Yekta et al. and involved 406 children with an average age of $8.56 \pm 2.4$ years. Among the participants, $18.5 \%$ had astigmatism, $16 \%$ myopia and $8.6 \%$ longsightedness [6].

Akinci et al. demonstrated that an ophthalmological assessment of every child with a disabilities is needed, since the incidence of refractive errors among them was higher than to their clinically healthy peers. He conducted the study on 724 children with intellectual disabilities, obtaining a prevalence of refractive errors in $77 \%$ of cases, vs. $42.4 \%$ in the control group, consisting of 151 children [7].

Ophthalmic screening is performed in many countries for the early detection of eye diseases among children. The presence of an uncorrected refractive error compromises the quality of life of these children already diagnosed with a disability. The pres- ence of several disabilities, including a visual one, can produce a cummulative effect, more than an additive one in the life of these children. The visual impairment secondary to an uncorrected refractive error exacerbates the impact of other disabilities [8]. The vitamin D level of 100 patients with intellectual and developmental disability was studied by McKinnon et al. and concluded that $83 \%$ of them had suboptimal level [9].

Our study concluded that children with disabilities and and without refractive errors have an optimal value of vitamin $\mathrm{D}$, while children with disabilities and with refractive errors have a normal value of vitamin D. The study of Daldal et al. found out only suboptimal vitamin D level in children with refractive errors [10].

There are no significant differences in the group of children with disabilities vs children without disabilities and various refractive errors such as hyperopia and myopia in terms of vitamin D levels in our study. However, children with disabilities and hyperopia have an optimal level of vitamin $\mathrm{D}$, while children with myopia and astigmatism from the same group have an acceptable plasma level of vitamin D. Vitamin D levels are optimal in clinically healthy children with hyperopia and astigmatism and acceptable in those with myopia. All the children have an acceptable level of vitamin $\mathrm{D}$, but non-significant $(\mathrm{p}=0.0978)$.

In our study it was observed that both groups of children, with disabilities and myopia and those without disabilities and myopia have a lower blood level of vitamin $\mathrm{D}$, these results confirm the observations of various internationally studies [3,9]. The higher prevalence of refractive errors in the group of children with disabilities as well as a lower overall level of plasma vitamin $\mathrm{D}$ in these children may be responsible for the increased prevalence of refractive disorders among them. Decreased plasma vitamin D levels are secondary to lower exposure to sunlight in combination with an inadequate intake $[11,12]$.

The literature is extremely extensive regarding the link between plasma vitamin D levels and the occurrence of myopia [2] and the fact that the human eye health is strictly dependent on vitamin D levels [3]. The study conducted by Reins et al. on 946 participants demonstrated that those with myopia have lower serum levels of vitamin D compared to nonmyopic participants, thus it is reasonable to conclude that the likelihood of developing myopia is indirectly proportional with vitamin D levels $[13,14]$.

Guggenheim et al. conducted a study using prospective data from the Avon Longitudinal Study of Parents and Children (ALSPAC) to demonstrate the 
protective effect of sunlight against the development of myopia [15]. Other studies have shown once again that the incidence of myopia decreases with increased serum vitamin D levels $[3,15]$.

Our study presents a statistical significant difference of vitamin D level between children with astigmatism. Moreover, McMillan et al. described that the lack of a sufficient level of vitamin D could be responsbile for astigmatism and myopia. Moreover, the McMillan et al. study also points out that the proper supplementation of this vitamin halts the progression and possibly even regression of myopia and astigmatism, thus confirming the beneficial role on the eye. The ability to prevent myopia and astigmatism can even be absolute [3].

Differences of vitamin D level can be suggestive for an incongruity of vitamin D metabolism in children with astigmatism. Inadequate plasmatic availablilty of vitamin D in those with astigmatism and myopia may be an explanation [3]. Moreover, McMillan et al. showed that one year supplementation of vitamin D produces modest refractive shift of astigmatism, findings correlated with topographical changes [3]. Adequate supplementation of vitamin D produces over time uniform optics of the cornea. The first modifications to appear is the reduction of irregular astigmatism and if there is any of an internal astigmatism, the corneal part takes a 90 -dregreee opposite counter balancing utility [3]. All changes in corneal shape and its mechanical properties are initiated at its periphery and then distribute towards the center. All of these changes may be done by the changes in the limbal stem cells which have mechanical properties. Limbal stem cells may exhibit corneal changes like a continuous moving signal or wave towards the center of the cornea.

Astigmatism is a common refractive error in children and its etiology is not yet well understood. In a study conducted on 28 pairs of twins in Jiangsu, China, between January 2008 and March 2009, peripheral venous blood of the mothers in the fourth to sixth month of pregnancy was collected as well as the umbilical venous blood of twins was collected at birth. Vitamin D level was correlated with astigmatism $(\mathrm{p}<$ 0.05 ). These findings suggest that the occurence of astigmatism may take place in accordance to the pregnangy nutritional status and nutrition of children after birth [16].

Tideman et al. conducted a study on 4,154 children located in Rotterdam, aged 6 years old, who were dosed vitamin D and concluded that there is a strong association between plasmatic vitamin D level, axial length of the eyeball and the occurrence of myopia [17]. Children with low plasmatic levels of vitamin D presented higher axial length, while those with higher levels of vitamin $\mathrm{D}$ had a lower risk for myopia (OR 0.64; IC 95\% 0.46-0.92). This association was still significant after adjustment for light exposure [17]. Vitamin D receptor polymorphism (VDR) was associated with low-moderate myopia in caucasians.

The link between near work and myopia is inconsistent [12] and another hypothesis for myopia is one in which the dopamine release can be influenced by the solar light. This theory was tested on chicks and for its confirmation, high intensity light was used. The study of Yazar et al. concluded that solar light is indeed involved in retarding the development of myopia in chicks and monkeys [18]. A lower vitamin D level alters the intracellular calcium, and thus affects the ciliary muscle contraction and relaxation and predisposes to myopia [19]. Another hypothesis states that vitamin $\mathrm{D}$ is involved in the mechanism of retinoscleral signals [20]. In the study conducted by Iqbal et al., children with myopia with age ranging from 5 to 15 years old had a vitamin D level of $14.95 \pm 3.75 \mathrm{ng} / \mathrm{ml}$, not being significant differences of vitamin D levels between myopes and the control group [21].

\section{CONCLUSIONS}

The group of children with disabilities had refractive errors twice as common. Children with disabilities have astigmatism as the most prevalent refractive disorder.

All the children with refractive errors have a lower level of vitamin D. The lowest significant level was identified in children with disabilities and astigmatism showing a possible connection between the two ones.

\section{Acknowledgement}

This paper benefited from financial support through the project "SmartDoct - High quality programs for PhD students and postdoctoral researchers of the University of Oradea for increasing the relevance of research and innovation in the context of the regional economy", ID / Project code: 123008, cofinanced by the European Social Fund through the Human Capital Operational Program 2014-2020. 


\section{REFERENCES}

1. Ezeh El, Ibanga AA, Duke RE. Visual status of special needs children in special education schools in Calabar, Cross River State, Nigeria. Niger Postgrad Med J. 2018 Jul-Sep;25(3):161-165.

2. Li J, Zhang Q. Insight into the molecular genetics of myopia. Mol Vis. 2017 Dec 31;23:1048-1080.

3. McMillan J. Spectrum of Darkness, Agent of Light: Myopia, Keratoconus, Ocular Surface Disease, and Evidence for a Profoundly Vitamin D-dependent Eye. Cureus. 2018 Jun 5;10(6):e2744.

4. Vora U, Khandekar R, Natrajan S, Al-Hadrami K. Refractive error and visual functions in children with special needs compared with the first grade school students in Oman. Middle East Afr J Ophthalmol. 2010;17(4):297-302.

5. Kaur G, Thomas S, Jindal M, Bhatti SM. Visual Function and Ocular Status in Children with Disabilities in Special Schools of Northern India. J Clin Diagn Res. 2016 Oct;10(10):NC01-NC04.

6. Yekta AA, Hashemi H, Shadalouee Z, Dadbin N, Ostadimoghaddam $\mathrm{H}$, et al. Distribution of Binocular Vision Anomalies and Refractive Errors in Iranian Children with Learning Disabilities, J Compr Ped. 2015;6(4):e32680.

7. Akinci A, Oner O, Bozkurt OH, Guven A, Degerliyurt A, Munir K. Refractive errors and ocular findings in children with intellectual disability: a controlled study. J AAPOS. 2008 Oct;12(5):477-81.

8. Ezeh El, Ibanga AA, Duke RE. Visual status of special needs children in special education schools in Calabar, Cross River State, Nigeria. Niger Postgrad Med J. 2018 Jul-Sep;25(3):161-165.

9. McKinnon I, Lewis T, Mehta N, Imrit S, Thorp J, Ince C. Vitamin D in patients with intellectual and developmental disability in secure in-patient services in the North of England, UK. BJPsych Bull. 2018 Feb;42(1):24-29.

10. Daldal H, Gokmen Salici A. Ocular Findings Among Patients with Vitamin D Deficiency. Cureus. 2021;13(5):e15159.

11. Pan CW, Qian DJ, Saw SM. Time outdoors, blood vitamin D status and myopia: a review. Photochem Photobiol Sci. 2017 Mar $16 ; 16(3): 426-32$.
12. Schmidt Azevedo P, Fock RA, Pereira FL, dos Santos PP, Ferro FC Sacco N, Polegato BF, Zornoff LM, Okoshi MP, Achterberg W, de Paiva SR. The evident and the hidden factors of vitamin D status in older people during COVID-19 pandemic. Nutrire. 2021;46(1):1.

13. Reins RY, McDermott AM. Vitamin D: Implications for ocular disease and therapeutic potential. Exp Eye Res. 2015;May;134:101-10.

14. Xiong S, Sankaridurg P, Naduvilath T, Zang J, Zou H, Zhu J, Lv M, $\mathrm{He} X, \mathrm{Xu}$ X. Time spent in outdoor activities in relation to myopia prevention and control: a meta-analysis and systematic review. Acta Ophthalmol. 2017;Sep;95(6):551-566.

15. Guggenheim JA, Williams C, Northstone K, Howe LD, Tilling K, St Pourcain B, McMahon G, Lawlor DA. Does vitamin D mediate the protective effects of time outdoors on myopia? Findings from a prospective birth cohort. Invest Ophthalmol Vis Sci. 2014;Nov 18;55(12):8550-8.

16. Zhou W, Ju R, Wu R, Li J, Zhang P. Astigmatism in twin infants is related to pregnant nutrition. Biomedical Research. 2014; 25(4):528-32.

17. Tideman JW, Polling JR, Voortman T, Jaddoe VW, Uitterlinden AG, Hofman A, Vingerling JR, Franco $\mathrm{OH}$, Klaver CC. Low serum vitamin $D$ is associated with axial length and risk of myopia in young children. Eur J Epidemiol. 2016 May;31(5):491-9.

18. Yazar S, Hewitt AW, Black LJ, McKnight CM, Mountain JA, et al. Myopia is associated with lower vitamin D status in young adults. Invest Ophthalmol Vis Sci. 2014 Jul;55(7):4552-9.

19. Annamaneni S, Bindu CH, Reddy KP, et al. Association of vitamin D receptor gene start codon (Fok1) polymorphism with high myopia. Oman J Ophthalmol. 2011;4:57-62.

20. Choi JA, Han K, Park YM, et al. Low serum 25-hydroxyvitamin D is associated with myopia in Korean adolescents. Invest Ophthalmol Vis Sci. 2014;55:2041-7.

21. Iqbal Y, Malik A, Shabbier R, Zaman A, Zia S, Talib M. Role of Vitamin D in Near Sightedness. Pak J Ophthalmol. 2020; 36(2):137-141. 